\title{
Place of demonstration experiment in geography lessons
}

\author{
Aleksander Lugovskoy ${ }^{1,2}$, Sergey Gildenskiold ${ }^{1}$, Aleksander Volgin $^{1}$, Petr Krylov ${ }^{1, *}$ \\ ${ }^{1}$ Moscow Region State University, Radio str., 10A, 105005, Moscow, Russia, \\ ${ }^{2}$ Moscow State University of Geodesy and Cartography, 4, Gorokhovsky Per., 105125, Moscow, \\ Russia
}

\begin{abstract}
In accordance with the standards of education for the development of cognitive activity and creative abilities, to work with a large amount of information and interact in a group, the paper suggests using the possibilities of a demonstration experiment in all courses of physical geography. In accordance with the standards of education for improving the quality of students' knowledge, developing their cognitive activity, creative abilities, the mechanism of forming positive motivation in the process of independent activity in the acquisition of new knowledge and creative approach to the learning process is shown. The conducted pedagogical research on the selection of the content and forms of organization of the demonstration experiment showed the possibility of forming critical thinking in students on the basis of experimental activities in geography lessons. A wide introduction of a demonstration experiment that brings the quality of the lesson and extracurricular work to a new level with the provision of differentiation and individualization of the learning process is proposed.
\end{abstract}

\section{Introduction}

The main task of education at the present stage of transformation of the educational system is to choose the areas of educational activities taking into account the individual interests of students. This implies a unity of upbringing, intellectual development system and level of competence. It is for this reason that modern education is aimed at the development of independent learning activities of students, which provides for the possibility of mobilization of intellectual potential to solve problems.

In accordance with the standards of education to improve the quality of knowledge of students, develop their cognitive activity and creative abilities it is important to guide the work on formation of positive motivation in the process of self-activities in learning new knowledge and creative approach to learning. Federal state standard of basic general education (FSS BGE) will allow to educate a new generation that is able to set and solve problems independently, achieving goals based on forecasting results, performing reflection of activity, working with a large amount of information, interacting in a group, finding solutions for conflicts with successful socialization in new conditions.

* Corresponding author: pmkrylov@yandex.ru 
In modern education, a special role is played by the formation of critical thinking, which is considered from various points of view, used cognitive strategies techniques. Developing training implies the formation of self-regulation in the process of competence formation. Students should be provided with a system of judgments used to analyze events and phenomena that justify conclusions, assessments, and interpretations.

The foundations of the theory of experimental activity are developed in the works of Y. G. Neuymin (1984), A.I.Rakitov (1969,1975), A.I. Uemov (1971), P. E. Sivokon (1968), G. I. Ruzavin (1974, 1999), M. E. Omelyanovsky (1961), M. A. Khramovich (1972) [1-9]. Thanks to experimental activities, a number of problems can be solved. By performing experiments, students do real intensive intellectual work and come to the solution of life problems.

Literature analysis allows students to independently find solutions to problems, support the result with rational justification and realize the possibility of different approaches in the process of solving them, logically prove and verify the correctness of the obtained algorithms, relying on critical thinking as a special type of activity that allows students to make their own judgments and form their own point of view (Buyanov A. O., Lugovskoy A.M., 2014)[10,11].

Charles Temple, Ginny Steele, and Kurt Meredith are considered to be the creators of the algorithm for forming critical thinking [12,13]. According to D. Halpern [14] in the process of critical thinking, we evaluate the results of our thought processes, the course of reasoning which leads to conclusions and an assessment of factors on the basis of which we make a decision. According to B. Bloom [15] for its development, it is necessary to form the function of analysis and synthesis, structuring of information and evaluating it at the skill level. R.Jackson [16] believes that for the formation of critical thinking, the following skills must be distinguished: finding analogies of the received information, assessment of the information for the problem statement, finding various alternative solutions for solving the problem, and theirs selecting according to the degree of realizability. The development of intelligence is revealed in close connection with the development of independence in the process of critical thinking. Knowledge creates motivation, without which it is impossible to think critically. Critical thinking, in his opinion, begins with setting goals and formulating tasks of the identified problem, the reasonableness of the process of cognition of the studied process or phenomenon. According to D. Dewey $[17,18]$, it is important to teach thinking, since thinking reflects the surrounding reality and reveals the connections between objects and phenomena. Focusing on problems encourages students' natural curiosity and encourages critical thinking. Experimental activity increases interest in the learning process and active perception of educational material, competence, independent analytical and evaluation work, forms communication skills and social activity. According to J. Bean the process of critical thinking is faced by the student in all the variety of problems and their assessment and choice [19].

To date, the issues of critical thinking technology formation are presented in the works of A.V. Istomin, G. Volkov, K. Popper, I. O. Zagashev, S. I. Zair-Bek, K. K. Foster, R. Bustrom [20-27]. It should be noted that there are different approaches and points of view in the identified technologies of critical thinking, perception, analysis, reliability assessment, identification of advantages and disadvantages, and determining the degree of error. Critical thinking is a person's cognitive culture. However, the aspects of its formation have not yet been studied and the methodology for forming critical thinking during the study of various subjects, in particular, geography, has not been developed (Grishaeva Y.M. and others, 2018) [28]. The theory of meaningful learning is based on the theory of Vygotsky L. S. [29-30], the ideas of P. Fress, J. Piaget [31], the theory of creative cooperation between teacher and student, the development of an analytical and creative approach to any material being studied. 
The analysis of the use of modern technologies of teaching and learning geography, the study of the practice of using experiments in teaching geography in different schools reveals a number of contradictions between:

- existing in practice supporting education focused on getting students ready-made knowledge, the reproductive nature of obtaining knowledge, and the need to develop independence, creativity, self-development of system thinking, as well as the ability to mobilize all their personal capabilities to solve various problems;

- the lack of methodological foundations of the experiment for a detailed and deep study of phenomena and an attempt to apply them in the process of teaching in geography lessons;

- the established traditional system of teaching geography using a full-scale experiment, which is focused on the "average" student and replaced by a computer learning experiment.

- lack of ability in modern schools to work with the information flow, express their thoughts and ideas on the basis of the organized experiment, formulate and solve problems, independently acquire knowledge, working together in groups, build constructive relationships with other students.

- observation, experience, reflection, reasoning, and communication as a guide to action and belief formation.

The problem of the research is to answer the questions as follows: what are the foundations of the theory of development of critical thinking technology of students using the experimental method in the study of geography; what methodological conditions for the development of various technologies of critical thinking of students, primarily collective, joint, individual, should be extremely necessary to implement during experimental work in geography lessons, as well as which of the components - procedural or substantive, are the most important in the methodology for the development of critical thinking technology of students in geography by means of experimental work.

The solution of the contradictions of the above approaches determines the relevance of the research, which consists in the development of critical thinking of students by means of experimental work.

\section{Materials and methods of the research}

Experiment and observation - both of these methods are widely used in the process of teaching geography. In addition, students have a certain stock of observations about the world around them. But at the same time, setting up an experiment is an important tool for a comprehensive, complete and deep knowledge of objects and phenomena. Through critical thinking, students get new ideas and through experimentation, they test, evaluate and develop them with subsequent application in practice. In this regard, experimental activity comes to the fore in the process of forming the thinking of an independent personality. The purpose of the study was to develop a method for using the demonstration experiment system to form students' critical thinking. The object of our research was the formation of critical thinking based on experimental activities in students in geography lessons at school, and the subject of the study was the use of experimental observation systems for the formation of critical thinking of students.

In the "One-time study" model (figure 1), also known as "only subsequent analysis", the following restrictions are used: the external condition, under the influence of various numerous factors, can be distorted; the absence of random selection; the observed are selected by the researcher at random or independently make a decision to join the group. Preliminary and final research within the same experimental group takes place for some time, the reliability of the conclusion is problematic due to the uncontrollability of extraneous factors. The "Static group" model implies an experimental and control group. 
The difference of the "Real experiment" model is the use of random selection techniques. In their application, the researcher randomly assigns units of observation into groups. The composition of models of the valid experiment included a preliminary and a final study using a control group. The group should be equal in number of students, age, academic performance and teacher training. The requirements of the experiment include that the results of the first cut should be slightly higher in the control group, and after the experiment - lower. Only in this case, the effectiveness of the proposed method will be proven. In the case of the final study model, it is a much simpler version.

During the entire time of the pedagogical experiment in $6^{\text {th }}$ classes, twenty demonstration experiments were conducted, most of which were conducted within the sections "Lithosphere", "Hydrosphere", "Atmosphere". With the help of experiments, students experimentally came to the answer to the question why the Earth is flattened at the poles, formed a definition of the concept of metamorphism and metamorphic rocks, formed ideas about the processes of mountain formation, weathering, erosion, air heating, identified the causes and consequences of these processes. In addition, during the pedagogical experiment, students independently experimentally proved the presence of atmospheric pressure on the Earth and found out the causes of wind formation. During the second half of the school year, a series of rather lengthy experiments on the topic "Soil" was conducted, which helped students to identify the main property of soils, as well as determine what features of soils will affect the development of the plant world.

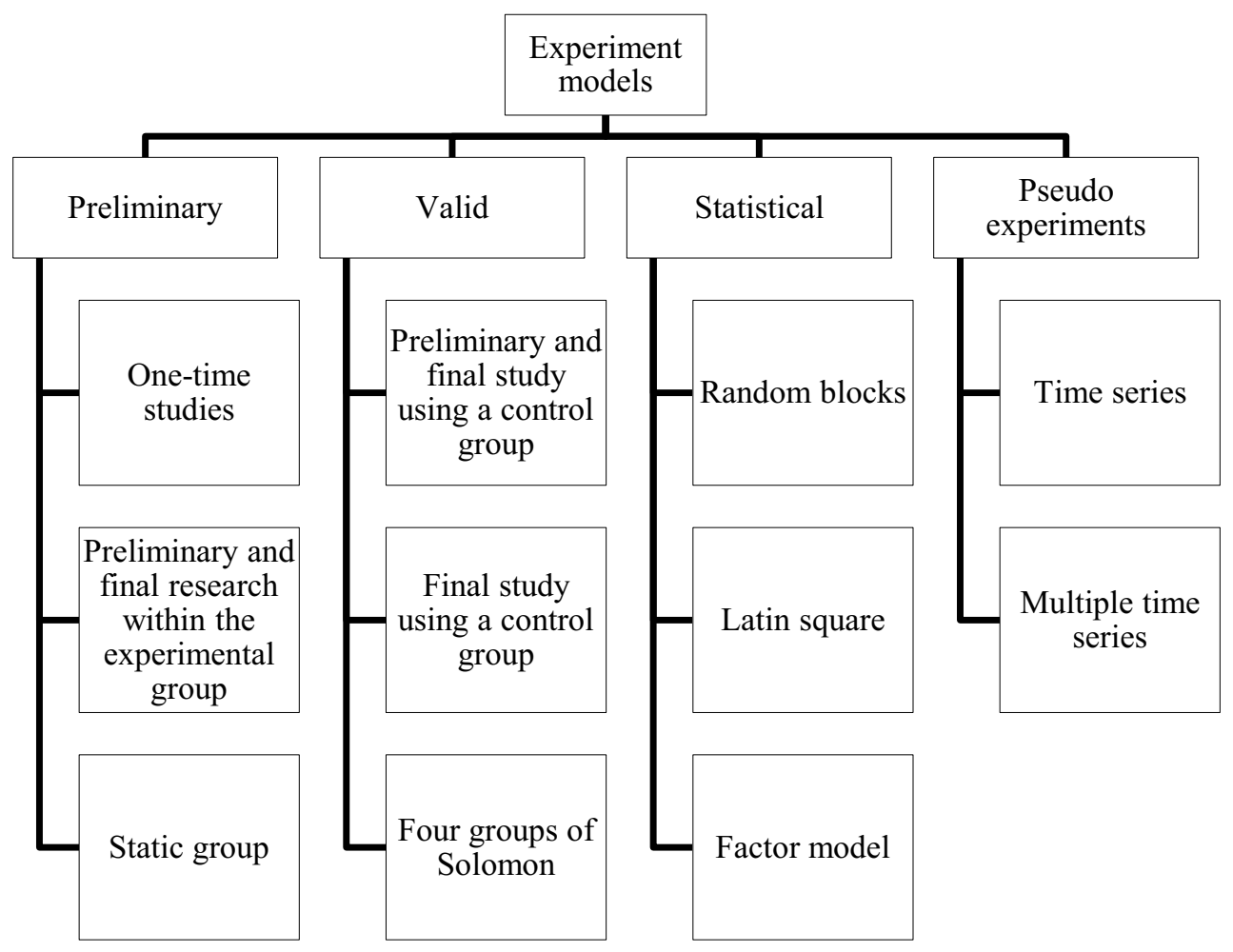

Fig. 1. Models of experiment. 
To confirm the effectiveness of the pedagogical experiment, data were provided on the following indicators: the success of the experiment in training and the effectiveness of the proposed method (1), which are calculated:

$$
y=\frac{k_{1}}{k_{2}}
$$

where, $Y$ - the coefficient of success of learning; $k_{1}$ - the coefficient of learning before the experiment; $k_{2}$ - the coefficient of learning after the experiment.

The data on the effectiveness indicator of the proposed method (2) was calculated:

$$
\eta=\frac{V_{1}}{V_{2}}
$$

where, $\eta$ - the coefficient of effectiveness of the proposed method; $Y_{1}$ - the coefficient of learning in the experimental class; $Y_{2}$ - the coefficient of learning in the control class.

If this coefficient is greater than one, then the applied method is more effective than the classical one. In this case, this coefficient shows the high efficiency of the method of experimental work in geography lessons.

\section{Results and discussion of the research}

Verification of the proposed experimental work was carried out at the stage of the training experiment. The effectiveness of the proposed experimental work was determined by such criteria as new knowledge (level of training), new experience (level of collaboration) when performing a training demonstration model experiment. Verification of knowledge acquisition in both control and experimental groups was carried out using test criteriaoriented tasks, according to the results of which we established a tendency to increase the level of theoretical knowledge and new experience in the experimental group of students, which is reflected in figure 2 .

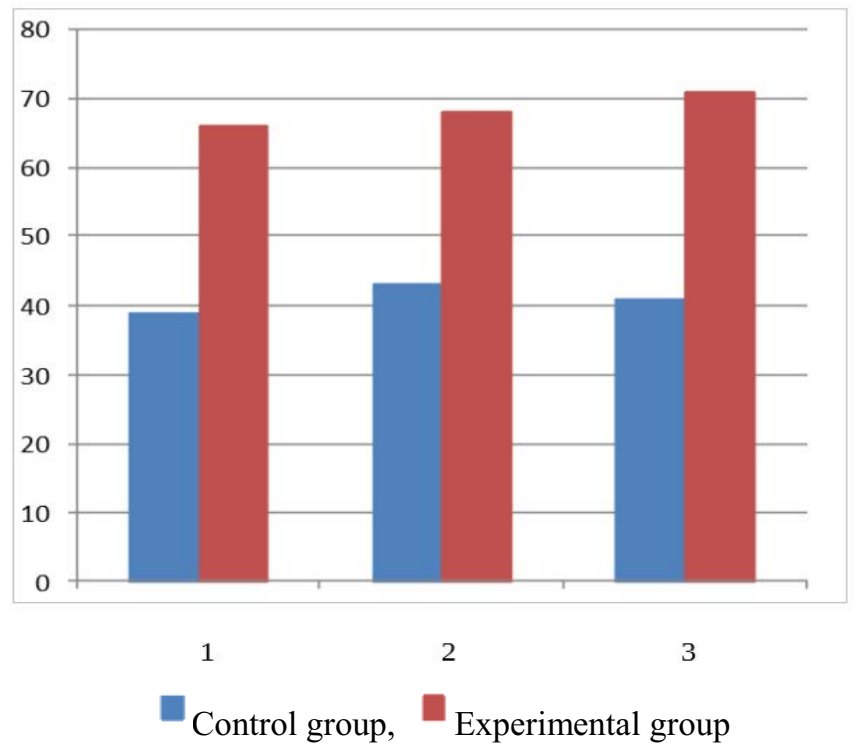

Fig. 2. Comparison of the levels of theoretical geographical knowledge in the experimental and control groups, \%. Symbols: sections 1- Lithosphere, 2- hydrosphere, 3- atmosphere. 
The results obtained during the experiment indicate an increase in the level of theoretical knowledge at a significant level in the study of geography, as well as the acquisition of new experience in performing a demonstration model experiment and computer experiment in the formation of the conceptual apparatus of the school geography course.

Based on the results of evaluating the levels of joint activity in geography lessons when working with a model experiment, we can note the transition from the reproductive to the research level, which allows us to talk about the individualization of students' educational work during the experiment.

The result of experimental work in schools in Moscow confirms the hypothesis of the study. The development of educational activities of students in geography lessons by means of experimental work is carried out on theoretical grounds, which determine the relationship between the forms of training organization, methods, tools, content and goals, taking into account the content of training and pedagogical technologies. It is based on the reflection of their application in the new conditions during the transition from reproducing activities to research, and the activation of experimental work in geography lessons brought to a new level the quality of both classroom and extracurricular work, and in addition, provided differentiation and individualization of learning.

As a result, the pedagogical experiment itself can be carried out in accordance with a certain model (statistical, actual, preliminary, pseudo-experimental) and, in the case of an experiment, with a control and experimental group, take into account that the groups should be similar in main indicators.

When conducting the experiment itself, three stages of pedagogical research were identified to confirm the research hypothesis: ascertaining, searching, and training. Certain tasks were set for each stage. As a result of the conducted pedagogical research, the results were obtained that confirm all the provisions of the research hypothesis, namely: the implementation of the development of educational activities by means of experimental work in geography lessons:

- promotes the application of previously unknown knowledge in new conditions, the transition to productive activity from reproductive;

- allows optimizing the educational process, improve the quality and efficiency, as well as improve the quality of graduate training;

- allows bringing both classroom and extracurricular independent activity of students in the study of the subject to a completely new level;

- contributes to the differentiation of independent work of students and at the same time will contribute in every possible way to the construction of an individual trajectory for students in the study of geography.

The theoretical analysis of the practical implementation of ways to solve the problem of research, as well as the current state of application of the demonstration experiment, showed that the independent implementation of the demonstration and model experiment provides students with subjectively new knowledge and experience.

The formation of critical thinking in students at school will be carried out more effectively if the formation of critical thinking is understood as one of the main goals of geography students at school and provides one of the stages of the methodology; the main didactic tool is a system of experiments that provides the formation of critical thinking of students; the use of experiments in geography lessons for the formation of cognitive activity is developed in accordance with the structure and content of the discipline, is determined by a system of methods and means of training, taking into account the level of the formation of critical thinking and geographical subject competence, since modern education should be subject-oriented, when students should deal with real-life problems.

At the same time, the effectiveness of the method can be evaluated by such means as the level of training, new experience, the level of joint activity of students when working 
with material models, as well as individual activities.

\section{Conclusion}

Finally, the results of experimental work carried out in different schools in Moscow confirm the hypothesis of the study. The development of educational activities of students in geography lessons by means of experimental work is carried out on theoretical grounds, which determine the relationship between the forms of training organization, methods, tools, content and goals, taking into account the content of training and pedagogical technologies. It is based on the reflection of their application in new conditions during the transition from generative activity to research and creative. The use of experimental work in geography lessons brought to a new level the quality of both classroom and extracurricular work, and in addition, provided differentiation and individualization of learning.

As a result, the pedagogical experiment itself can be carried out in accordance with a certain model (statistical, actual, preliminary, pseudo-experimental) and, in the case of an experiment, with a control and experimental group, take into account that the groups should be similar in main indicators.

When conducting the experiment itself, three stages of pedagogical research were identified to confirm the research hypothesis: ascertaining, searching, and training. Certain tasks were set for each stage. As a result of the conducted pedagogical research, the results were obtained that confirm all the provisions of the research hypothesis, namely: the implementation of the development of educational activities by means of experimental work in geography lessons:

- promotes the application of previously unknown knowledge in new conditions, the transition to productive activity from reproductive;

- allows optimizing the educational process, improve the quality and efficiency, as well as improve the quality of graduate training;

- allows bringing both classroom and extracurricular independent activity of students in the study of the subject to a completely new level;

- contributes to the differentiation of independent work of students and at the same time will contribute in every possible way to the construction of an individual trajectory for students in the study of geography.

The theoretical significance of the research is to develop a concept and model for the development of critical thinking technology for students studying geography using the means of experimental work, which allows them to devote much more time to independent activities in the pedagogical process, which, in turn, helps them independently acquire new knowledge and gain experience in performing natural experiments. Development of the theory and methodology of geography of the research of the essence of processes using experimental activities for the formation of critical thinking technology and justification of experimental activities in the course of educational activities in geography lessons, which requires reflex critical thinking, which is the most valuable for education and development will help in solving the problems of transition from reproductive to research activities (productive) when using the experiment in geography lessons, independent acquisition of new knowledge, development of critical thinking, creative abilities, reflexive skills, independence and activity.

\section{References}

1. Y.G. Neuymin, Models in science and technology: history, theory, practice (L., Nauka, 
1984)

2. A.I. Rakitov, Anatomy of scientific knowledge (M., Politizdat, 1969)

3. A.I. Rakitov, Principles of scientific thinking (Moscow, Politizdat, 1975)

4. A.I. Uemov, Logical foundations of the modeling method (M., Mysl', 1971)

5. P.E. Sivokon, Methodological problems of natural science experiment (Moscow, MSU publishing house, 1968)

6. G.I. Ruzavin, Methods of scientific research (M., Mysl', 1974)

7. G.I. Ruzavin, Methodology of scientific research: textbook for universities (M., UNITY-DANA, 1999)

8. M.E. Omelyanovsky, The problem of visibility in physics 11, 20 (1961)

9. M.A. Khramovich, Scientific experiment, its place and role in cognition (Minsk, Publishing house of BSU, 1972)

10. A.O. Buyanov, A.M. Lugovskoy, Problems of regional ecology 3, 146 (2014)

11. A.M. Lugovskoy, A.O. Buyanov, Modern problems of science and education 2, 262 (2014)

12. C. Temple, Peremena , 15 (2005)

13. C. Temple, J.L. Steele, K.S. Meredith, Critical thinking- deep methodology. Textbook 4 (Moscow, publishing house of INTA "Open society", 1998)

14. D. Halpern, Psychology of critical thinking (Saint Petersburg, "Peter" publishing house, 2000)

15. B.S. Bloom, Taxonomy of educational objectives: The classification of educational goals: Handbook I, cognitive domain (New York, Longman, 1994)

16. R.H. Johnson, Some Observations about Teaching Critical Thinking. CT News. Critical Thinking Project (Sacramento, California State University, 1985)

17. J. Dewey, Psychology and pedagogy of thinking (M., Edition of the partnership "Mir", 1919)

18. J. Dewey, Psychology and pedagogy of thinking (Moscow, Labyrinth, 1999)

19. J. Bean, Engaging Ideas: The Professo's Guide to Learning in the Classroom (San Francisco, Jossey-Bass, 1996)

20. A.V. Istomin, Experiment and innovations in school 6, 76 (2009)

21. E.N. Volkov, Bulletin of the University of Nizhny Novgorod named after Lobachevsky N.I. Series: Social sciences 2(42), 199 (2016)

22. K. Popper, Evolutionary epistemology and the logic of social sciences (Editorial URSS, 2000)

23. D. Kluster, Russian language magazine 29 https://rus.1 sept.ru/article.php?ID=200202902

24. I.O. Zagashev, S.I. Zair-Bek, Critical thinking: technology of development (Saint Petersburg: Alliance "Delta", 2003)

25. S.I. Zair-Bek, Head teacher 4, 66 (2005)

26. S.I. Zair-Bek, I.V. Mushtavinskaya, Development of critical thinking in the classroom (Moscow, Prosvescheniye, 2004)

27. K.K. Foster, Peremena 4, 38 (2004)

28. R. Bustrom, Development of creative and critical thinking (Moscow, "Open society" publishing house Inta, 2000) 
29. Y.M. Grishaeva, I.V. Wagner, Z.N. Tkacheva, A.M. Lugovskoy, P.N. Moro, South of Russia: ecology, development 13(3), 159 (2018) https://doi.org/10.18470/1992-10982018-3-159-166

30. L.S. Vygotsky, Collected works: In 6 volumes (Moscow, Pedagogika, 1982)

31. L.S. Vygotsky, Pedagogical psychology (M., Pedagogika, 1991)

32. P. Fress, J. Piaget, Experimental psychology (M., Progress, 1970) 